satisfied with simply expressed explanations without the backing of mathematical theory.

In view of the space at his disposal the author has wisely decided to confine himself to the general methods of analysis, illustrated by application to a few typical devices.

A list of standard treatises on acoustics, mechanics and electricity is given in the many footnotes, and these should be of great service to those students who wish to pursue the study of particular topics to a further stage.

T. M. YARWOOD

\section{Methods of Mathematical Physics}

Vol. 1. By R. Courant and D. Hilbert. (First English edition translated and revised from the German Original.) Pp. $\mathrm{xv}+561$. (Now York: Interscience Publishers, Inc.; London: Interscience Publishers, Ltd., 1953.) 9.50 dollars.

TNGLISH translations of standard German books 4 are always welcome, and in view of the current demand for mathematics in scientific and technical applications it is particularly pleasing to have this translation. The original text was reviewed at length in Nature $(153,633 ;$ 1944) by Prof. Milne-Thomson, and readers are referred to this for details concerning the present volume. For the translation, it is sufficient to say that there are numerous additions and modifications, the most extensive of which is an appendix (to Chapter 7) by Wilhelm Magnus. This concerns the transformation of spherical harmonics. A pleasing feature is that the bibliography has been brought up to date. The printing is excellent.

$$
\text { L. S. GODDARD }
$$

\section{Electrostatique et Magnétostatique}

Par Émile Durand. Pp. xii +774. (Paris: Masson et Cie., 1953.) 6335 francs.

7 HIS work is an uneasy compromise between a text-book and a reference book. Students who like spoon-feeding will be delighted by the author's painstaking elaboration of the subject and discussion of many examples in which all calculations are given to the last detail. Experimental physicists and engineers will find in it a wealth of up-to-date information about the mathematical basis of the most varied applications of the electrostatic and magnetostatic fields. But one should not look in it for a deeper treatment of the fundamentals of the subject.

Within these limitations this book will certainly be very useful and can be warmly recommended. It is, of course, difficult to be original in treating such $a_{b}$ classical subject, and the author's exposition follows the traditional lines. Nevertheless there are a few happy innovations. The Giorgi system of units is consistently used and many tables of typical constants are given, probably for the first time, in these rational units. An interesting chapter describes in a very practical spirit the numerical methods of calculation of field distributions. The treatment of the magnetic properties of matter, and especially that of ferromagnetism (a domain to which the French school has made a brilliant contribution), is particularly well done.

Although the exposition is generally clear, the style is rather pedestrian and there is no sparkle in the book of that elegance which used to be characteristic of the French scientific tradition. It was a shock to discover that the author is so estranged from this tradition that he barbarously denotes the tartrate rendered famous by Pasteur as "sel de Rochelle".
Radloactivity and Radioactive Substances By Sir James Chadwick. Fourth edition. Pp. xv + 120. (London: Sir Isaac Pitman and Sons, Ltt., 1953.) 12s. $6 d$. net.

7 HIS text-book has stood the test of time and in spite of the remarkable developments in the field of nuclear physics during the past fifteen years it still remains one of the best introductions to the fundamentals of the subject. It was first published in 1921 and has now reached the fourth edition. The arrangement of the material in the new edition is substantially the same as that in the original edition; but where necessary the subject-matter and data have been modified or supplemented to bring it up to date. ' In the chapter on measurements more modern methods and techniques have been introduced and $a$ new chapter on nuclear structure, in which nuclear stability, artificial radioactivity and nuclear fission are discussed, has been added. These revisions and additions are by Prof. J. Rotblat, who it will be remembered worked for many years at Liverpool under Sir James Chadwick and who is thus well qualified to revise a book originally written by Sir James.

S. WeINTROUB

\section{Optics}

The Technique of Definition. By Arthur Cox. Tenth edition. Pp. 376. (London and New York: The Focal Press, 1953.) 17s. 6d. net.

TF the popularity of a book can be judged by the 1 number of editions published, then this book must indeed be very popular, for it now appears in its tenth edition, the first having been published in 1943.

The work is devoted entirely to what are undoubtedly the most precious and vital parts of any camera, namely, lenses, and the subject is treated very exhaustively and thoroughly, in a language which the ordinary photographer can understand without becoming involved in scientific formulæ.

The full study of lenses is admittedly highly technical; but the treatment here is so skilfully done that the reader cannot fail to become intensely interested, and he soon finds himself able to understand how his lens works and why, what may be expected of it and what is the best type to use. The gap between the scientific approach of the designer and the proctical man who uses the lens has been bridged, and the photographer can now have an added zest and intelligence for his work, based on a more intimate knowledge of his chief tool.

It is not only the photographer who can derive benefit from the book. There are also excellent articles on the defects of lenses, such as aberrations of various types, distortion, ete., which will be found useful to any student of optics whether interested in photography or not.

T. M. YaRwOOD

Advances in Applied Mechanics

Edited by Richard von Mises and Theodore von Kármán. Vol. 3. Pp. $x+324$. (New York : Academic Press, Inc.; London: Academic Books, Ltd., 1953.) 9 dollars.

THIS third volume carries on the admirable tradition already established. The present book is almost entirely devoted to problems of fluid dynamics except for a long, careful, interesting and important article by Dr. Geiringer giving a very comprehensive account of some recent results in the theory of an ideal plastic body. There is also a short 